\title{
PERFIL EPIDEMIOLÓGICO DAS INTERNAÇÕES EM UM PRONTO SOCORRO DO MUNICÍPIO DE SÃO PAULO
}

\author{
Cilene Aparecida Costardi Ide* \\ Angela Maria Geraldo Pierin* \\ Kátia Grillo Padilha* \\ Eliane Corrêa Chaves*
}

IDE, C.A.C.; PIERIN, A.M.G.; PADILHA, K.G.; CHAVES, E.C. Perfil epidemiológico das internaçð̃es em um pronto socorro do município de Săo Paulo. Rev. Esc. Enf. USP, São Paulo, 22(3) 257-271, dez. 1988.

Neste estudo foram caracterizadas as internações ocorridas num Pronto Socorro do Municipio de São Paulo, no ano de 1984, considerando-se as causas de internação segundo sua natureza.

UNITERMOS: Emergência. Pacientes-Internação.

\section{INTRODUÇÃO}

As mudanças econômicas culturais e comportamentais, que ocorrem numa sociedade, geralmente trazem como consequência alteraçð̋es no perfil epidemiológico das diferentes doenças que acometem seus indivíduos.

Uma sociedade como a nossa, que historicamente situa-se numa fase de reavaliação de conceitos e hábitos e de reestruturação de sua economia vem, provavelmente, sofrendo modificaçðes bastante rápidas e significativas no panorama de saúde de sua população.

Nesse contexto, as investigaçðes epidemiológicas desempenham papel relevante na prática dos profissionais, pois embasam cientificamente as prioridades e a adequação da assistência à população, além de nortear o ensino e a pesquisa das áreas envolvidas.

No âmbito da assistência hospitalar, as modificaçðes epidemiológicas entre as doenças tornam-se mais evidentes no ambulatorio e Pronto Socorro, isto porque ambos representam as principais vias de acesso à utilização hospitalar. A análise do atendimento nesses dois setores torna possível, portanto, caracterizar e priorizar o atendimento à saúde de determinada população.

No que diz respeito particularmente ao ensino de enfermagem, assim como de qualquer outra profissão ligada à saúde, esta caracterização do atendimento hospitalar assume importância significativa, na medida que possibilita direcionar o ensino para as reais necessidades de saúde da população e, conseqüentemente, adequar a prática profissional.

* Enfermeiras. Professores-Assistentes do Departamento de Enfermagem Médico-Cirúrgica da Escola de Enfermagem da USP - disciplina Enfermagem Médico-Cirúrgica. 
Considerando a crescente importância dos acidentes, dos atos de violência, da inadaptação do indivíduo ao seu próprio meio ambiente, agravados pela situação quantitativa e qualitativamente insuficiente do sistema preventivo de saúde, parece lícito supor que o estudo do atendimento no Pronto Socorro seja prioritário na tarefa de investigação e caracterização do tipo de assistência hospitalar que a população mais solicita.

Diante disso e visando contribuir para a adequação e correlação do ensino e da prática da enfermagem, com base em dados científicos, este estudo foi realizado com os objetivos de:

- caracterizar numericamente o atendimento ocorrido no Pronto Socorro do Instituto Central do Hospital das Clínicas da Faculdade de Medicina da Universidade de São Paulo (PS ICHC FMUSP), no período de 1980 a 1985;

- detectar a proporção entre as doenças de causas naturais e não naturais nas internaçðes ocorridas;

- verificar a distribuição das afecçðes segundo sua natureza.

\section{METODOLOGIA}

O estudo, de caráter retrospectivo, foi baseado em levantamento realizado pela Divisão de Arquivo Médico do HCFMUSP, e abrangeu a totalidade dos pacientes atendidos nos PS desse hospital no período de 1980 a 1985, com ênfase nas internações ocorridas de janeiro de 1984 a janeiro de 1985.

\subsection{Caracterização do Serviço}

O Serviço do PS ICHC FMUSP faz parte do complexo H C, hospital geral de ensino, sendo o Pronto Socorro de referência da região da Grande São Paulo.

Abrange subunidades especializadas, incluindo área cirúrgica, médica, neurológica, urológica, endoscópica, obstétrica, de queimados, de tratamento intensivo e unidade de retarguarda.

Quanto ao fluxograma, a partir de uma primeira triagem médica, o paciente recebe atendimento inicial e, quando necessário é encaminhado para a subunidade específica, segundo o comprometimento apresentado.

Ressalta-se que, muitas vezes, o paciente apenas recebe tratamento sintomático, sendo liberado logo em seguida. Os casos de maior comprometimento podem sofrer um processo de internação que obedece aos seguintes critérios: tempo de permanência superior a 12 horas; pacientes submetidos ou aguardando cirurgia; portadores de procedimentos invasivos (intubação, drenos, cateteres, etc...); pacientes acometidos por parada cárdio-respiratória, em coma, com crise de agitação psicomotora, com descompensação diabética, sob terapêutica com drogas vasoativas e com conṿulsoes.

\subsection{Classificação das doenças}

Para essa categorização, optou-se por uma primeira divisão a partir da natureza da doença. Assim, preliminarmente, as afecç̧ðes foram subdivididas em naturais, ou seja, aquelas decorrentes de alteraçôes orgânicas internas e em não naturais, oca- 
sionadas por agentes externos causados por acidentes diversos. Os agrupamentos posteriores foram elaborados com base no Manual de Classificação Estatística Internacional de Doenças, Lesðes e Causas de Óbito (1978) conforme o descrito a seguii.

\subsubsection{Doenças de causas não naturais}

Nesse grupo foram incluídos:

- acidentes decorrentes de: quedas diversas, colisão, atropelamento, capotamento, choque de autos, desmoronamento, danos provocados por instrumentos de trabalho, queimadura, explosão, picada ou mordedura;

- agressoes diversas causadas por: soco, estupro, ferimento por arma de fogo (FAF), ferimentos por arma branca (FAB) e pauladas;

- traumas que causarão hemorragia interna, choque hemorrágico, fraturas diversas e politraumatismo;

- ferimentos acidentais em diferentes segmentos do corpo;

- Intoxicação exógena decorrente da ingestão de produtos químicos diversos, álcool e medicamentos.

\subsubsection{Doenças de causas naturais}

Nesse contingente foram agrupadas as diversas alteraçōes sistêmicas (digestiva, respiratória, cárdio-circulatória, gênito-urinária, neurológica, dermatológica (pele e subcutâneo) osteoarticular e conjuntiva, hematológica e do sensorio), abrangendo os processos inflamatórios, infecciosos, obstrutivos, vasculares, além de alteraçðes anátomo-funcionais. Complementando este agrupamento, foram também considerados processos neoplásicos, psicopatias, desequilíbrio nutricional e hidroeletrolítico, anomalias congênitas, orgãos ou tecidos substituidos por transplante e sinais e sintomas mal definidos. Especificação de cada ítem encontra-se relacionada no anexo I.

\subsection{Tratamento estatístico}

Os dados obtidos foram analisados em índices absolutos e percentuais.

\section{RESULTADOS E DISUSSÃO}

Os resultados apresentados a seguir configuram o perfil epidemiológico dos atendimentos efetuados.

Talvez o fator mais representativo desses dados seja o significativo número de pessoas que anualmente procuram esse Pronto Socorro, em torno de 1\% da população da Grande São Paulo, notando-se tendência crescente nesse atendimento.

A defasagem entre a procura do atendimento e a totalidade de internaçðes pode ter duas conotaçðes. A primeira relaciona-se à capacidade de absorção desse serviço em face da demanda, já que os recursos humanos, materiais e a planta física são por si só fatores limitantes, justificando, inclusive, a pequena variação do número de internaçðes ocorridas nesses anos. 
Um segundo aspecto a ser considerado talvez possa retratar procura inadequada de atendimento em Pronto Socorro, porque, na verdade, a grande maioria $(94,5 \%)$ desse contingente não ficou internado. Essa situação seria reflexo de uma estrutura de saúde distorcida e limitada na atuação preventiva, levando a população a buscar pronto atendimento em hospital.

T A B E L A 1

PACIENTES ATENDIDOS NO PS ICHC FMUSP NO PERIODO DE 1980-1985

\begin{tabular}{l|rccc|cc}
\hline \multicolumn{1}{r|}{ Paciente } & \multicolumn{2}{|c}{ Internado } & \multicolumn{2}{c|}{ Não internado } & \multicolumn{2}{c}{ Total } \\
Período & n? & $\%$ & n? & $\%$ & n? & $\%$ \\
\hline 1980 & 8479 & $(5,8)$ & 135488 & $(94,2)$ & 143967 & $(100,0)$ \\
1981 & 7152 & $(4,6)$ & 147387 & $(95,4)$ & 154539 & $(100,0)$ \\
1982 & 9367 & $(6,3)$ & 138571 & $(93,7)$ & 147938 & $(100,0)$ \\
1983 & 10328 & $(6,1)$ & 158685 & $(93,9)$ & 169013 & $(100,0)$ \\
1984 & $\mathbf{9 7 2 3}$ & $(5,2)$ & 177491 & $(94,8)$ & 187214 & $(100,0)$ \\
1985 & 10093 & $(5,3)$ & 179598 & $(94,7)$ & 189691 & $(100,0)$ \\
\hline Total & 55142 & $(5,5)$ & 937220 & $(94,5)$ & 992362 & $(100,0)$ \\
\hline
\end{tabular}

T A B E L A 2

DISTRIBUIÇÃO DAS DOENÇAS SEGUNDO SUA NATUREZA PS ICHC FMUSP, $01 / 1984$ a $01 / 1985$.

\begin{tabular}{l|cc}
\hline Natureza & no & $\%$ \\
\hline Não naturais & 6550 & $(56,4)$ \\
Naturais & 5056 & $(43,6)$ \\
\hline TOTAL & 11606 & $(100,0)$ \\
\hline
\end{tabular}

$\overline{\mathrm{X}}=32$ internações $/$ dia

Verifica-se, pelos dados da tabela 2, que a maioria das doenças decorre de causas não naturais $(56,4 \%)$, confirmando o crescente índice de violência, acidentes de trânsito e homicídios em nosso meio (KOIZUMI, 1984; JORGE, 1980(a,b); PETZHOLD, 1985).

Outro aspecto a ser ressaltado relaciona-se à proporcionalidade entre as duas causas de internação, aparentemente contradizendo a finalidade básica de um Pronto Socorro, ou seja, o atendimento imediato: para salvaguardar a vida do paciente, numa situação agủda (PEDROSO, 1963). Nesse sentido, o fato de 43,6\% dos pa- 
cientes terem procurado esse atendimento em virtude de: exacerbação ou descompensação de alteraçðes orgânicas prévias, ou por agravos decorrentes de condiçðes de saneamento básico inadequados, parece refletir algumas distorçðes assistenciais. Dentre elas, a precariedade de um Sistema de Saúde que realmente exerça a sua função preventiva, possibilitando tanto o atendimento precoce quanto o acompanhamento posterior. Essa análise encontra respaldo em consideraçðes feitas por KEDY (1981), que também considera o aumento do uso do Pronto Socorro como esmagador e decorrente da falta, qualitativa e quantitativa, de serviços ambulatoriais oferecidos à comunidade.

Por outro lado, ainda podem caracterizar a dificuldade do cliente que, mesmo atendido, pode não ter condição sócio-econômica ou cultural de efetuar os cuidados prescritos, o que causaria diminuição significativamente a aderência ao seu tratamento prescrito, o que acarretaria como conseqüência, a agudização ou cronicidade da doença.

$\mathrm{O}$ terceiro aspecto a ser analisado refere-se ao expressivo contingente dos 11.606 internados. Na verdade, 32 pessoas por dia, em média, foram agudamente retiradas do seu contexto de vida, ocasionando comprometimentos pessoal e social; deve ainda ser considerado o alto custo operacional de um atendimento quase sempre não resolutivo.

Vale ainda ressaltar que esse Serviço não é, necessariamente a única porta de entrada do sistema hospitalar, pois muitos doentes podem ter acesso à internação por via ambulatorial. Salienta-se, também, que atendimentos específicos contam com serviços especializados do próprio Complexo Hospital das Clínicas, a saber: Pronto Socorro de Cardiologia, de Ortopedia e de Pediatria. Conseqüentemente, a procura de atendimento emergencial deve ultrapassar, em muito, os números aqui obtidos e pode, ainda, influenciar nos perfis qualitativo e quantitativo descritos.

T A B E L A 3

DISTRIBUIÇÃO DAS DOENÇAS NÃO NATURAIS SEGUNDO A CAUSA. PS ICHC FMUSP, 01/1984 a 01/1985.

\begin{tabular}{l|rr}
\hline Causa & $\mathrm{n}$ \% & $\%$ \\
\hline ferimentos & 3701 & 56,5 \\
traumas & 1285 & 19,6 \\
agressóes & 817 & 12,5 \\
acidentes & 684 & 10,5 \\
intoxicação exógena & 49 & 0,7 \\
corpos estranhos & 14 & 0,2 \\
\hline TOTAL & 6550 & 100,0 \\
\hline
\end{tabular}

As condiçðes adversas abrangendo as situaçōes de trabalho e trânsito, o convívio inadequado com a tecnologia e a violência da vida urbana, possibilitando tanto 
os comportamentos anti-sociais quanto os desequilibrios emocionais, parecem ter sido os principais fatores desencadeantes dessas internaçðes.

Nesse quadro, a relação homem-meio ambiente parece ser sempre conflitante. Os ferimentos $(56,5 \%)$ decorrem principalmente de acidentes ocasionados por situaçðes inadequadas de convívio ou de atenção no manuseio do arsenal de trabalho ou da atividade doméstica. Os traumas $(19,6 \%)$, juntamente com os acidentes $(10,5 \%)$ refletem, basicamente, a interação da pessoa com o veículo em todas as esferas que compoem a interrelação homem (motorista ou pedestre), veículo e via, abrangendo, ainda, em menor intensidade, outras morbidades (quedas, desmoronamento, queimaduras, picadas ou mordeduras, entre outras). JORGE (1981), estudando as causas de mortes acidentais, concluiu que estas representam os maiores percentuais entre as causas violentas, destacando os acidentes de trânsito e, dentre eles, os atropelamentos como os mais letais. As agressōes (12,5\%) também refletem diferentes componentes da relação insatisfatória entre o homem e seu semelhante. Ainda no estudo feito por JORGE (1981), foi enfatizado que a mortalidade por homicídios aumentou $290 \%$ de 1960 a 1975 , sendo que o meio mais utilizado para sua realização foi a arma de fogo.

Os ferimentos por arma branca, arma de fogo, ou devidos a estupro, entre outras manifestaçð̄es de agressividade, podem ter como causa várias situaçð̃es (abandono, privação, segregação, marginalização, enfim, um grupo não absorvido pelo sistema vigente), porém sempre o mesmo fim: a desagregação da personalidade e um conflito crescente que pode culminar com a violência.

Os dados da Tabela 4 evidenciam que as afecçōes do sistema digestivo $(32,6 \%)$, as vasculares $(11,5 \%)$ e os processos neoplásicos $(10,7 \%)$ são os mais expressivos numericamente.

A elevada incidência de agravos comprometendo os diferentes sistemas orgânicos possibilitam algumas reflexסes. Preliminarmente, parece retratar um paciente que não teve acesso ou possibilidade de continuidade de tratamentos iniciais, chegando a tal fase de descompensação que exigiu atendimento emergencial, invasivo e auto limitado, que não soluciona os problemas de base. O custo da terapêutica medicamentosa, a pouca ênfase nos programas educativos no que diz respeito a detecção e controle e a dificuldade do cliente em compreender a linguagem dos profissionais de saúde também seriam fatores a justificar a elevada incidência e a descompensação das diferentes patologias.

Por outro lado, a condição sócio-econômica e ambiental também tem sua parcela de responsabilidade nesse quadro. Psicopatia, desnutrição, moléstias infectocontagiosas, parasitoses incluidas nos distúrbios do sistema digestivo, entre outras, evidenciam a precariedade da qualidade de vida dessa população.

Contudo, se o compromisso do Sistema de Saúde, abrangendo prevenção e tratamento, não pode ser omitido, o papel do cliente reforçando esse contexto também deve ser analisado. Somente uma postura passiva, a pouca conscientização acerca dos seus direitos, a pouca representatividade popular na deliberação e avaliação dos serviços de atendimento, enfim, a compreensão do componente político da saúde ainda pouco desenvolvida é que podem contribuir para a perpetuação desse quadro.

\section{CONSIDERAÇÕES}

A reflexão acerca desses dados possibilita ao profissional de saúde a adequação da sua prática, a partir do perfil esboçado, abrangendo: 
DISTRIBUIÇÃO DAS DOENÇAS DE CAUSAS NATURAIS SEGUNDO O COMPROMETIMENTO ORGÂNICO. PS ICHC FMUSP, 01/1984 a 01/1985.

\begin{tabular}{|c|c|c|}
\hline Comprometimento orgânico & no & $\%$ \\
\hline afecçôes do sistema digestivo & 1.648 & 32,6 \\
\hline afecções vasculares & 581 & 11,5 \\
\hline processos neoplásicos & 539 & 10,7 \\
\hline afecções do sistema gênito urinário & 381 & 7,5 \\
\hline afecções respiratórias & 295 & 5,8 \\
\hline complicações pós procedimentos cirúrgicos & 279 & 5,5 \\
\hline afecções cárdio circulatórias & 256 & 5,2 \\
\hline afecções neurológicas & 210 & 4,2 \\
\hline afecçðes da pele e do subcutâneo & 203 & 4,0 \\
\hline sinais e sintomas mal definidos & 165 & 3,2 \\
\hline moléstias infecto-contagiosas & 149 & 2,9 \\
\hline disfunçð̃es metabólicas & 93 & 1,8 \\
\hline psicopatias & 71 & 1,4 \\
\hline órgãos ou tecidos substituídos por transplantes ou artefatos & 55 & 1,1 \\
\hline afecções hematológicas & 38 & 0,8 \\
\hline afecções dos órgãos dos sentidos & 30 & 0,6 \\
\hline afecções do sistema ósseo-articular e conjuntivo & 29 & 0,5 \\
\hline desequilibrio nutricional & 21 & 0,4 \\
\hline desequilíbrio hidro-eletrolítico & 10 & 0,2 \\
\hline anormalias congênitas & 3 & 0,1 \\
\hline TOTAL & 5056 & 100,0 \\
\hline
\end{tabular}

- o reconhecimento do caráter paliativo dessa assistência, pois, como nos demais casos, o problema de base, ou seja, a falência do sistema social vigente não foi solucionada;

- a necessidade de desempenho, senão isento de julgamento, pelo menos suficientemente crítico para reconhecer nesses individuos, independente de sua situação de agressor ou agredido, a condição de vítima desse mesmo sistema;

- o compromisso na atuação conjunta para melhoria das condiçðes de vida de todos;

- e, finalizando, a percepção da fragilidade de qualquer sistema educativo de caráter estático, unilateral, que não implique num processo multiprofissional de assistência, pois, para uma sociedade em constante transformação, nenhuma receita se aplica de maneira satisfatória, nenhum conhecimento, por mạis abrangente que seja, se não for dinâmico, sensível e reflexivo, não terá condiçðes de retroalimentar-se.

Nesse contexto, emerge a força tanto da pesquisa epidemiológica, que possibilita a deteç̧ão dessas alteraçðes, como do suporte sociológico e psicológico embasando uma postura crítica e compromissada. 


\section{CONCLUSÕES}

Em face dos objetivos propostos neste estudo, os dados referentes ao atendimento ocorrido no PS ICHC FMUSP conduziram às seguintes conclusðes:

- o número de atendimentos, no período de 6 anos, abrangeu 992.362 pessoas. Destas, a grande maioria $(94,3 \%)$ não foi internada;

- as internaçoes ocorridas no período de janeiro de 1984 a janeiro de 1985 perfizeram um total de 11.606 . Destas, $56,4 \%$ tiveram como origem da doença causas não naturais e $43,6 \%$, causas naturais;

- entre as causas das doenças não naturais, as mais freqüentes foram, respectivamente: os ferimentos $(56,5 \%)$; os traumas $(19,6 \%)$; as agressðes $(12,5 \%)$ e acidentes diversos $(10,5 \%)$;

- dentre as doenças de causas naturais, as afecçðes do sistema digestivo foram as mais freqüentes $(32,6 \%)$, seguidas pelas vasculares $(11,5 \%)$ e processos neoplási$\cos (10,7 \%)$.

IDE, C.A.C.; PIERIN, A.M.G.; PADILHA, K.G.; CHAVES, E.C. Epidemiological profiles of cases admitted to an Emergency Attendance Unit in the city of São Paulo. Rer Rev. Esc. Enf. USP, São Paulo, 22(3):257-271, Dec. 1988.

This study describes cases registered an Emergency Attendance Unit in the city of São Paulo, during 1984, taking into account the main cause of admittance.

UNITERMS: Emergency. Patient admission.

\section{REFERÊNCIAS BIBLIOGRÄFICAS}

KEDY, V. Organização de um serviço de emergência - aspecıos legais. Rev. Paul. Hosp., São Paulo, 29(3):80-4, 1981.

KOIZUMI, M.S. Aspectos epidemiológicos dos acidentes de motocicleta no Municipio de Sàu Paulo. São Paulo, 1984. 140 p. (Tese de doutoraniento - Faculdade de Saúde Pública da USP).

MANUAL da classificação estatistica internacional de doenças, lesỏes e causas de óbito. Sào Paulo, Centro Brasileiro de Classificação de Doenças, 1978. 815 p.

JORGE, M.H.P. Mortalidade por causas violentas no Municipio de São Paulo, Brasil: 1 - Mortess violentas no tempo. Rev. Saúde Publ., Săo Paulo, 14(3):343-57, 1980(u).

JORGE, M.H.P.M. Mortalidade por causas violentas no Município de São Paulo, Brasil: 11 - Mortes acidentais. Rev. Saúde Publ., São Paulo, 14(4):475-508, 1980.(b)

JORGE, M.H.P.M. Mortalidade por causas violentas no Municipio de São Paulo, Brasil. III Mortes intencionais. Rev. Saúde Publ., São Paulo, 15(2):165-93, 1981.

PEDROSO, O.P. Organização de um serviço de emergência numa comunidade de 500.000 habitantes. Rev. Paul. Hosp., São Paulo, 11(5):12-4, 1963.

PETZHOLD Uma abordagem sistêmica da dinâmica da segurança de trânsito. Rio de Janeiro, 1985. 129 p. (Tese de doutoramento - Escola de Engenharia da UFRJ). 


\section{ANEXO I}

\section{CARACTERIZAÇĀO DAS DOENÇAS DE CAUSAS NATURAIS}

\section{Afeç̧̋es vasculares}

- amputação

- microembolização

- obstruçōes arteriais

- lesठes artério-venosas

- fístulas artério-venosas traumáticas

- aneurismas

- pseudoaneurismas

- processos inflamatórios

- varizes

- úlceras

- trombose venosa

- embolia

- obstrução de enxerto

- erisipela

- ateromatose

- arteriosclerose

- doença de Budd-Chiare

- hemorroidas

- varizes de esôfago e fundo gástrico

- linfedema

- úlcera pós fasciotomia

\section{Afeç̧ð̃es neurológicas}

- miastenia

- hidrocefalia

- atrofia cerebral

- compressão medular

- plegias

- bexiga neurogênica

- coma

- convulsão

- hiperestesia

- contusão cerebral

- hematoma craniano

- meningite pós-operatória 
- epilepsia

- hipertensão intracraniana

- edema intracraniano

- fistulas

- mielorradiculite

- hérnia de disco

- febre tifoide

- shiguelose

- enterite

- gastro-entero-colite aguda

- tuberculoses diversas

- Hansen

- septicemia

- gangrena

- hepatite

- viroses

- miocardiopatia chagásica

- deficiência imunológica

- parasitose e verminose
- empiema sub dural

- síndrome de Brawn Sefward

- meningomiocele

- espinha bifica

\section{Moléstias infecto-contagiosas}

- megalon chagásico

- aortite sifilítica

- neurolues

- herpes zoster

- conjuntivite

- artrite gonocócica

- leptospirose

- ptiriase

- monilíase

- blastomicose

- tricomoníase

- AIDS

- meningite

\section{Disfunçðes metabólicas}

- hipo e hipertireoidismo

- diabetes

- nefropatia diabética

- intoxicação endógena

\section{Desequilibrios nutricionais}

- desnutrição

- beri-beri

\section{- caquexia}

- anorexia 
- doenças de cadeia pesada

- obesidade
- histrocitose

- intolerância a glicose

\section{Desequilibrio hidroeletrolitico}

- alcalose

- desidratação

- hiperamilasemia

- hipopotassemia

\section{Afeç̧ðes hematológicas}

- anemias

- pancitopenia

- hemofilia

- coagulaçăo intra-vascular disseminada

- leucocitose

- mielofibrose hepática

- cisto de baço
- ganglio cervical calcificado

- adenite mesentérica

\section{Afeç̧ões dos órgãos dos sentidos}

- endoftalmite

- glaucoma

- catarata

- amaurose

- úlcera

- ceratite

- desepitelização

- oftalmoplegia

- desorganização do globo ocular

- celulite de olho

- perda vitrea 


\section{Afeç̧ões cardio-circulatórias}

- valculopatias

- infarto do miocardio

- insuficiência coronariana

- miocárdio esclerose

- aneurisma de ventrículo

- embolia pulmonar

- cor pulmonale
- endocardite

- arritmias

- insuficiência cardiaca congestiva

- hipotensão

- choque

- sopros

- átrio-ventrículo único

- embolia gordurosa

- parada cardio-respiratória

\section{Afecções respiratórias}

- pneumonias

- broncopneumonia

- bronquite

- traqueobronquite

- enfisema

- doença pulmonar obstrutiva crônica

- fístulas

- aderências

- empiema

- derrames

- hemo e pneumotórax

- abscesso

atelectasia
- edema agudo de pulmão

- insuficiência respiratória aguda

- encarceramento

- estenose de traquéia e laringe

- broncoespasmo

- mediastinite

- infecção vias aéreas superiores

\section{Afecções do sistema digestivo}

- megaesôfago chagásico

- esofagite

- perfuração do esôfago

- sindrome de Malory Wills
- evisceração

- peritonite

- necroses

- apendicite 
- úlcera gástrica

- gastrite

- úlcera duodenal

- estenose de anastomose

- papilite

- fístula gástrica

- necrose de estômago

- hemorragias

- vômitos

- disfagia

- abdomen agudo perfurativo

- cirrose hepática e biliar

- coma hepático

- hipertensão portal

- sindrome hepato-renal

- colicistites

- cólica biliar

- coledocolitíase

- vesícula hidrópica

- perfuração de vias biliares

- fístulas

- colangite

- estenose de colédoco

: ictericia obstrutiva

- pancreatite

- fígado policístico

- hepatomegalia

- esplenomegalia

- hepatite
- hernias

- doença de Crohn

- necrose de alça

- insuficiência vascular mesentérica

- diarréia crônica

- intusecção

- ileo paralítico

- volvo sigmóide

- oclusão intestinal

- fecaloma

- divertículos

- colite aguda

- megacolon chagásico

- dilatação duodenal

- fissura anal

- peritonite

- brida

- hemoperitônio

- abdomen agudo

- prolapso de reto e de colostomia

- perfuração do reto, colon e delgado

- abscessos

- melena

- sindrome de má absorção

- distensão abdominal

- deiscência de anastomoses

- alteraçðes no sistema de derivação peritônio-jugular

\section{Afecçōes reno-urinárias}

- insuficiência renal aguda

. infarto renal

- insuficiência renal crônica

- cistite

- pielonefrite

- rutura de bexiga

- abscessos

- fistulas 
- hidronetrose

- calculose

- cisios

- obstruçào de ureter

- hidroureter

- refluxo vésico-ureteral

- pioureter

- retenção urinária

- estenose de junçào uretero-pélvica

- anúria

- deiscência de anastonose

- necrose de escroto e de anastomoses
- hematúria

- hiperplasia de próstata

- finose

- orquite

- priapismo

- torsão de testículo

- hipospádia

- rim multilobulado

- extrofia vesical

- válvula de uretra posterior

- cólica renal

\section{Afecções ginecológicas}

- anexite

- abscesso de ovário

- abscesso pélvico

- prolapso de útero

- rutura de períneo

- cisto de ovário

- hematosalpinge

- bridas

- gravidez

- infecção puerperal
- leucorréia

- hemorragia uterina

- prenhez ectópica

- aborto infectado

- peritonite

- deiscência de sultura reto-bexiga

- descolamento prematuro de placenta

- eclâmpsia

- cesária

- óbito fetal

\section{Afecções do tegumento cutâneo-mucoso}

- abscessos

- impetigo

- celulite

- cisto pilonidal

- fístula cutâneo-mucosa

- psoríase

- escara
- úlcera

- área cruenta

- vitiligo

- disqueratose familiar congênita

- necrose de segnientos

- edema localizado 
Afeç̧ões do sistema ósteo-articular e conjuntivo

- lupus

- sindrome de Sgogren

- artrites

- fascite necrotizante
- osteomielite

- osteoporose

- amiloidose

- cisto de Baker

- dor

\section{Psicopatias}

- demência senil

- sindrome de abstinência

- esquizofrenia

- depressão

- psicose maníaco depressiva

- crise histérica

- alcoolismo

Recebido para publicação em $26 / 02 / 87$. . 